Research Paper

\title{
Optimization of the Ternary Combinations of Rockwool-PAN-Cellulose Fibers for the best Fade-Recovery Performance in Nonasbestos Organic Brake Pad Composite
}

\author{
Putri Nawangsari ${ }^{1)}$ Jamasri $^{1)}$ Heru S B Rochardjo $^{1 *}$ Arif Tri Waskito ${ }^{2)}$ \\ 1) Mechanical and Industrial Engineering Department, Universitas Gadjah Mada, Jl. Grafika No. 2, Yogyakarta 55281, Indonesia \\ (*E-mail: heru-sbr@ugm.ac.id) \\ 2) Indo Bintang Mandiri Co. Delta Silicone 3, Jl. Soka Blok F-20 No. 8B-5, Cikarang Pusat, Bekasi, Indonesia
}

Received on March 18, 2020

\begin{abstract}
This experimental study aimed to assess the friction performance of nonasbestos organic (NAO) brake pad based on ternary combinations of rockwool, PAN, and cellulose fibers under fade-recovery conditions. Four compositions with varying volume fractions of rockwool, PAN, and cellulose fibers were fabricated. The tribological properties of the sample were tested using JF160 Chase tester based on SAE J661. Optimally, the sample with a synergistic combination of rockwool, PAN, and cellulose fibers in proportion of 10:4:4 vol.\% exhibited the best overall friction performances. This combination could be used as NAO brake pad material for reliable, efficient, safe, and comfortable braking operations.
\end{abstract}

KEY WORDS: materials, composite material, friction, rockwool, PAN, cellulose, fade-recovery [ D3]

\section{Introduction}

Nonasbestos organic (NAO) brake pads have been rapidly developed. They are designed to substitute harmful asbestos brake pads. NAO brake pads have a low braking noise and a low wear rate ${ }^{(1)}$. However, they do not work well at high temperatures because they lose braking efficiency, which is known as brake fade phenomenon ${ }^{(2)(3)}$. Brake fade is not only dangerous but also a cause of premature failure in the braking system.

Efforts have been devoted to developing NAO brake pads to obtain an excellent braking performance measured by various factors, such as steady and high friction of coefficient $(\mathrm{CoF})$, low wear loss, less braking vibration and noise, low-fade, and fast recovery under extensive braking operations, and to ensure reliable, efficient, safe, and comfortable braking (4)(5). With these complex requirements, NAO brake pads comprise various ingredients that function as a binder, filler, friction modifier, and reinforcement ${ }^{(6)(7)}$. Among these materials, fiber reinforcement has a major role in complementing the drawbacks of resin binder and other ingredients (8) at high temperatures, which influence friction performance. Therefore, the type, relative amount, and synergistic combination of fiber reinforcement in a brake pad can control the friction performance of the brake pad (9)(10). Appropriate fiber reinforcements with high thermal stability should be selected to control the friction performance at high-temperatures.

Rockwool fiber is a mineral fiber with superior properties, such as high thermal resistance of up to $1273^{\circ} \mathrm{K}{ }^{(8)}$ and low thermal conductivity of about $0.045 \mathrm{~W} / \mathrm{mK}$ that can reduce the heat transfer from a disc to a pad ${ }^{(11)}$. Although rockwool fiber produces thermal stability in wide temperature ranges. However, Ozturk et al. (10) reported that the addition of 30 vol.\% rockwool fiber in a brake friction material only increases the friction coefficient until temperature reaches $473^{\circ} \mathrm{K}$ and enhances the specific wear rate up to $623{ }^{\circ} \mathrm{K}$. Rockwool fibers, when appropriately combined with other fibers, tend to improve the friction performance, particularly fade and wear resistances ${ }^{(\mathbf{8})}$. Bernard and Jayakumari ${ }^{(\mathbf{1 2})}$ reported that the binary combination of $8 \mathrm{wt} . \%$ rockwool fiber and $12 \mathrm{wt} . \%$ steel fiber show optimum friction coefficient and wear resistance. Liu et al. ${ }^{(13)}$ studied the binary combination of rockwool fiber and glass fiber on tribological properties. They concluded that the presence of rockwool fiber enhances the friction coefficient at hightemperatures. A synergistic combination of 9 wt.\% rockwool fiber and glass fiber favors the best wear resistance with the formation of large and smooth contact plateaus.

The potential combination of rockwool fiber with organic fibers in brake pad materials has yet to be evaluated. PAN and cellulose fibers are organic fiber that can be combined with rockwool fiber because they benefit brake pad materials. PAN fiber is efficient improving recovery performance, although it causes a high wear when it is combined with Lapinus ${ }^{\left({ }^{(8)}\right.}$. PAN fiber enhances the strength of a friction material because this fiber forms rigidmolecules at above $453^{\circ} \mathrm{K}^{(14)}$. Meanwhile, cellulose fiber added to friction materials improves the resilience of friction materials, reduces brake squeal ${ }^{(14)}$, and offers a good recovery performance. However, Ho et al. (15) reported that the content of $10 \mathrm{wt} . \%$ cellulose fiber in copper-phenolic resin-based friction material shows high wear and a significant fade.

Brake pad materials based on a combination of binary/ternary fiber reinforcement are expected to improve friction performance and wear resistance. Hence, the combination of rockwool-PANcellulose fibers may enhance friction performance and wear. However, studies have yet to asses the fade and recovery behavior as a comprehensive evaluation of friction performance in NAO 


\section{Putri Nawangsari et al / International Journal of Automotive Engineering}

Vol.11, No.2(2020)

brake pads containing a combination of rockwool-PAN-cellulose fibers. This experimental study aimed to obtain an optimal combination of rockwool-PAN-cellulose fibers and examine the correlation of compositional variables with friction performance attributes, namely: friction coefficient $(\mathrm{CoF})$ performance $(\mu \mathrm{p})$, $\mathrm{CoF}$ fluctuations, $\mathrm{CoF}$ variability, $\mathrm{CoF}$ stability, \% fade performance, $\%$ recovery performance, and wear, under fade and recovery conditions.

\section{Experimental Methods}

\subsection{Material and sample preparation}

The formulation of the composite sample consists of 13 ingredients, and 10 of them are kept constant ( 82 vol.\%). The remaining 18 vol.\% constitutes a combination of rockwool, PAN, and cellulose fibers with different ratios, as shown in Table 1.

Table 1 Fiber reinforcement contents of the composite sample

\begin{tabular}{|c|c|c|c|c|}
\hline \multirow{2}{*}{$\begin{array}{c}\text { Ingredients } \\
\text { (vol. \%) }\end{array}$} & \multicolumn{4}{|c|}{ Composite Sample } \\
\cline { 2 - 5 } & CPR-01 & CPR-02 & CPR-03 & CPR-04 \\
\hline \hline Cellulose & 4 & 4 & 4 & 4 \\
\hline $\begin{array}{c}\text { Polyacrylonitrile } \\
\text { (PAN) }\end{array}$ & 8 & 6 & 4 & 2 \\
\hline Rockwool & 6 & 8 & 10 & 12 \\
\hline Other ingredients & 82 & 82 & 82 & 82 \\
\hline
\end{tabular}

The other ingredients in the composite samples were phenolic resin (25 vol.\%), friction dust (10 vol.\%), $\mathrm{BaSO}_{4}$ (20 vol.\%), graphite (8 vol.\%), $\mathrm{MoS}_{2}$ (3 vol.\%), hBN (3 vol.\%), copper (5 vol.\%), $\mathrm{SiO}_{2}$ (4 vol.\%), $\mathrm{MgO}$ (2 vol.\%), and $\mathrm{Al}_{2} \mathrm{O}_{3}$ (2 vol.\%).

Four composite samples with different formulations were manufactured in five-step process: weighing, mixing, hot pressing, postcuring, and finishing. The fabrication details of the composite samples were described in our previous study (16). Sample dimension of $25.4 \mathrm{~mm} \times 25.4 \mathrm{~mm} \times 7.5 \mathrm{~mm}$ were obtained after the manufacturing process (Fig. 1). The surface morphology of the four samples after postcuring was analyzed with an optical microscope (Olympus PM-10. AD). This test aimed to determine the distribution of fibers in the resin binder.

\subsection{Thermal properties of the composite samples}

The thermal properties of the composite samples were tested thermogravimetric analysis (TGA) and differential scanning calorimetry (DSC). The sample was subjected to TGA by using a Mettler Toledo TGA in accordance with ASTM E1131-14 to investigate the weight loss of the composite samples as a function of temperature. A sample test of $20 \mathrm{mg}$ was heated from $303^{\circ} \mathrm{K}$ to $873^{\circ} \mathrm{K}$ with a heated rate of $283^{\circ} \mathrm{K} / \mathrm{min}$ under nitrogen atmosphere. Meanwhile, DSC was conducted by utilizing a Shimadzu DSC-60 Plus to examine the thermal profile of the composite samples under the dynamic thermal conditions. A sample test of $8.9 \mathrm{mg}$ was placed inside aluminum crucible pan, and another crucible pan without any sample was used as a reference. Furthermore, the sample was heated from $303{ }^{\circ} \mathrm{K}$ to $873{ }^{\circ} \mathrm{K}$ under a nitrogen atmosphere with a flow rate and temperature rate of $30 \mathrm{~mL} / \mathrm{min}$ and $283^{\circ} \mathrm{K} / \mathrm{min}$, respectively.

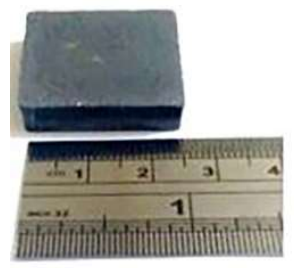

(a)

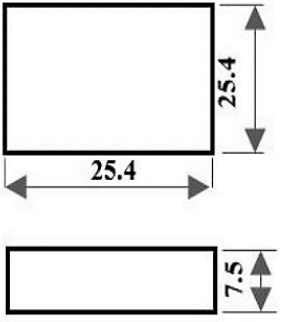

(b)
Fig. 1 Composite sample after postcuring: (a) fabricated sample, and (b) sample dimension

\subsection{Tribological properties of the composite samples}

The tribological properties of the samples were evaluated using a JF160 Chase tester (DC400V) in accordance with SAE J661. The machine scheme is shown in Fig. 2. The dimensions of the test sample were $25.4 \mathrm{~mm} \times 25.4 \mathrm{~mm}$. The test sample was positioned at a distance of $150 \mathrm{~mm}$ in the inner part of the drum and then hydraulically pressed against a drum that rotated at load and shear speeds of $660 \mathrm{~N}$ and $411 \mathrm{rpm}$, respectively. The details of the order of the testing procedures based on SAE J661 were presented in our previous study ${ }^{(16)}$. Each formulation of the composite samples was tested three times. After the test procedure was completed, the friction performance in terms of the $\mathrm{CoF}$ performance $(\mu \mathrm{p})$, CoF fluctuation, CoF stability, CoF variability, $\%$ fade performance, and $\%$ recovery performance was calculated on the basis of the actual test (two fade and two recovery cycles). The wear sample was determined by measuring the difference in thickness and the weight of the sample before and after the friction test. Subsequently, the wear surface morphology of the sample was analyzed using scanning electron microscopy (JEOL type JSM6510LA).

The CoF performance ( $\mu$ p) of the sample was calculated on the basis of the average friction coefficient in the condition of two fade cycles and two recovery cycles.

The CoF fluctuation, CoF stability, CoF variability, $\%$ fade performance, and \% recovery performance of the sample was calculated with Equation (1), (2), (3), (4), and (5), respectively:

$$
\begin{aligned}
& \text { CoF fluctuation }=\mu_{\max }-\mu_{\text {min }} \\
& \text { CoF stability }=\frac{\mu_{\mathrm{p}}}{\mu_{\max }} \\
& \text { CoF variability }=\frac{\mu_{\max }-\mu_{\min }}{\mu_{\mathrm{p}}} \\
& \% \text { fade performance }=\frac{\mu_{\mathrm{p}}-\mu_{\min (\text { fade })}}{\mu_{\mathrm{p}}} \\
& \% \text { recovery performance }=\frac{\mu_{\max (\text { recovery })}}{\mu_{p}}
\end{aligned}
$$

\section{Results and Discussion}

3.1. Surface morphology of the composite sample after postcuring

Fig. 3 exhibits the surface morphology of the four samples after postcuring. Copper agglomerations are insufficient evenly 


\section{Putri Nawangsari et al / International Journal of Automotive Engineering}

Vol.11, No.2(2020)

dispersed in all the samples. PAN, cellulose, and rockwool fibers are also not uniformly dispersed with the formation of widespread fiber agglomeration in CPR-02/CPR-03/CPR-04.

Generally, non-uniformly distributed particles or agglomeration is influenced by many factors, such as particle size, size distribution, temperature, and material properties ${ }^{\left({ }^{17}\right)}$. Copper agglomeration formed in all the samples may be due to the fine copper particles size of about 325 mesh ASTM with a large surface area than its volume. Therefore, van der Waals force increases particle interaction and then induces agglomeration (18). Meanwhile, fiber agglomerations in CPR-02/CPR-03/CPR-04 increase as the content of rockwool fiber increases. This finding may be due to the inherent fiber-agglomeration morphology of rockwool fiber. As such, rockwool fiber is not uniformly dispersed in resin binder.
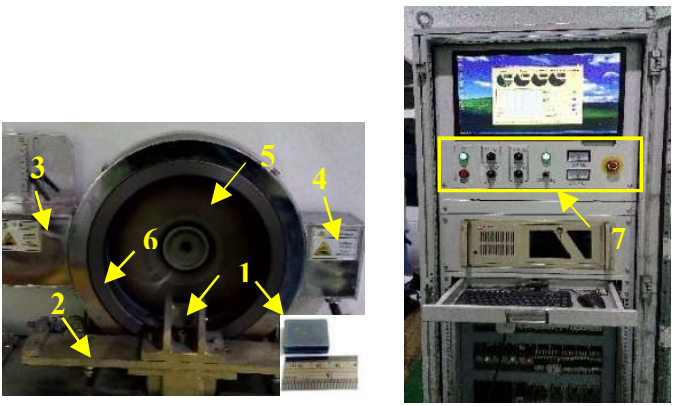

Fig. 2 Schematic of JF160 Chase tester: (1) test sample, (2) loading arm, (3) heater, (4) blower, (5) drum disc, (6) sliding track, (7) control system

\subsection{Thermal properties of the composite samples}

TGA thermograms are presented in Fig. 4. All the samples decompose gradually in a temperature range of $303{ }^{\circ} \mathrm{K}$ to $523{ }^{\circ} \mathrm{K}$
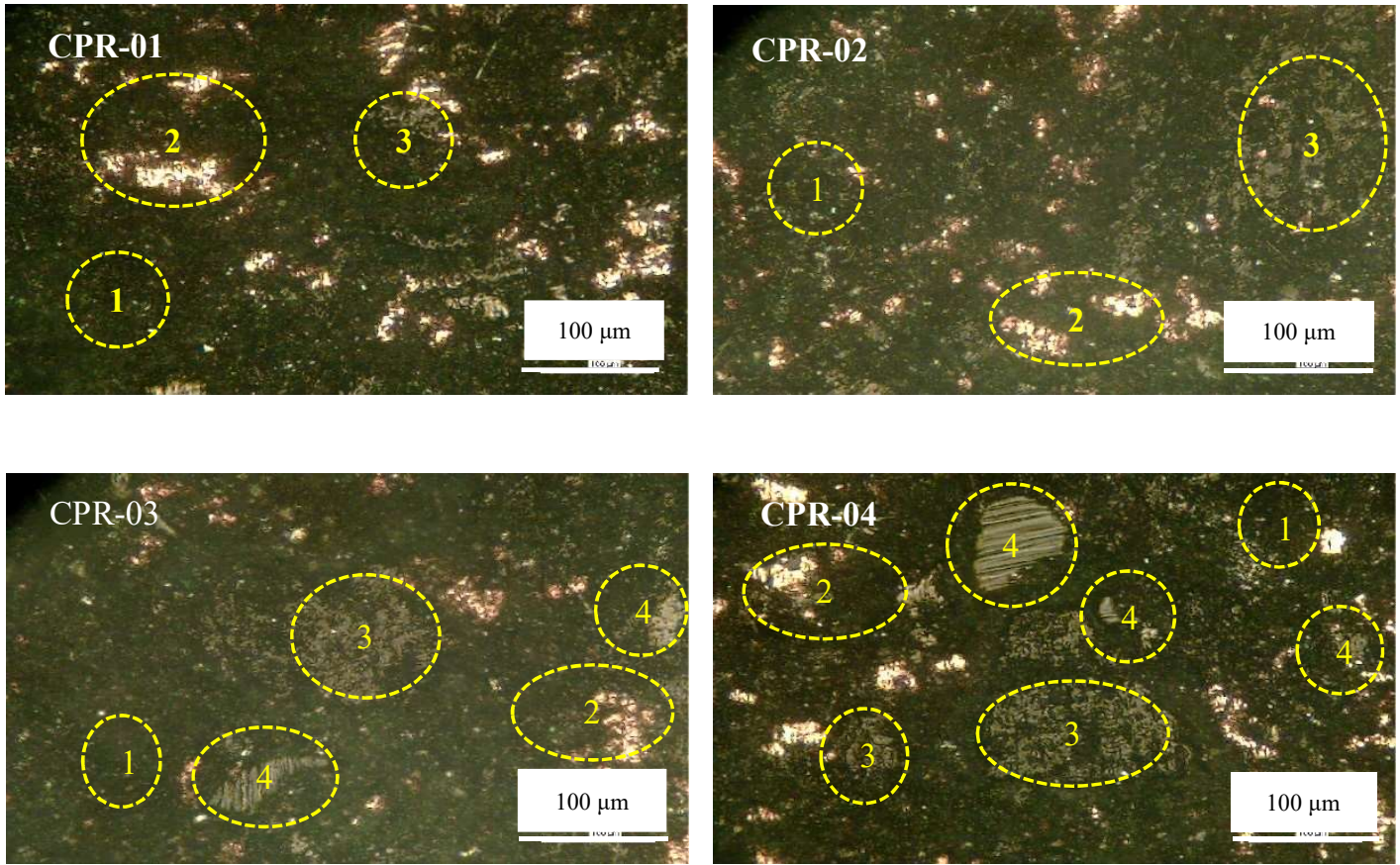

Fig. 3 Optical microscopy images of composite samples: (1) binder, fillers, and friction modifiers; (2) copper; (3) PAN and cellulose

Fig. 3 Optical microscopy images of composite samples: (1) binder, fillers, and friction
fibers; and (4) rockwool fiber and their weights decrease by $\sim 1 \%$. Subsequently, the decomposition rate of all the samples increases drastically in the temperature range of $523^{\circ} \mathrm{K}$ to $873^{\circ} \mathrm{K}$, and the weights of CPR- 01 , CPR-02, CPR-03, and CPR-04 reduce by about $9.99 \%, 8.62 \%$, $8.46 \%$, and $7.68 \%$, respectively.

The insignificant weight reduction of the four samples $(\sim 1 \%)$ is related to the evaporation of water ${ }^{(19)}$ and gas from unreacted phenol monomers and formaldehyde during curing ${ }^{(20)}$. Meanwhile, an increase in the decomposition rate followed by a drastic weight reduction in the temperature range of $523^{\circ} \mathrm{K}$ to $873{ }^{\circ} \mathrm{K}$ is related to the emission of gas components $\left(\mathrm{CO}_{2}, \mathrm{CO}\right.$, and $\left.\mathrm{H}_{2}\right){ }^{(21)}$ from the thermal degradation of other organic ingredients, namely: friction dust, PAN, and cellulose fibers in this study.

Residual weight is directly related to the thermal stability of the sample, that is the higher the residual weight of the sample is, the higher the thermal stability will be. The TGA test results reveal that the residual weights of the four samples show the following trend: CPR-04 > CPR-03 > CPR-02 > CPR-01. Therefore, the enhancement of the content of rockwool fiber combined with 4 vol.\% cellulose fiber and the decrease in the content of PAN fiber increases the thermal stability of the sample. This finding is mainly attributed to the presence of alumina-silicate elements $\left(\mathrm{SiO}_{2}\right.$, $\mathrm{Al}_{2} \mathrm{O}_{3}, \mathrm{Fe}_{2} \mathrm{O}_{3}, \mathrm{CaO}$ ) in rockwool fiber ${ }^{(22)}$ because they aid in thermal resistance and contribute to the thermal stability of the samples. CPR-04 sample has the best thermal stability among the samples.

The DSC thermograms of the four samples are presented in Fig. 5. These thermograms show the heat flow behavior of the sample toward an increase in temperature, and an exothermic peak phase transition of each sample is observed. Subsequently, DSC test results are presented in Table 2. 


\section{Putri Nawangsari et al / International Journal of Automotive Engineering}

Vol.11, No.2(2020)

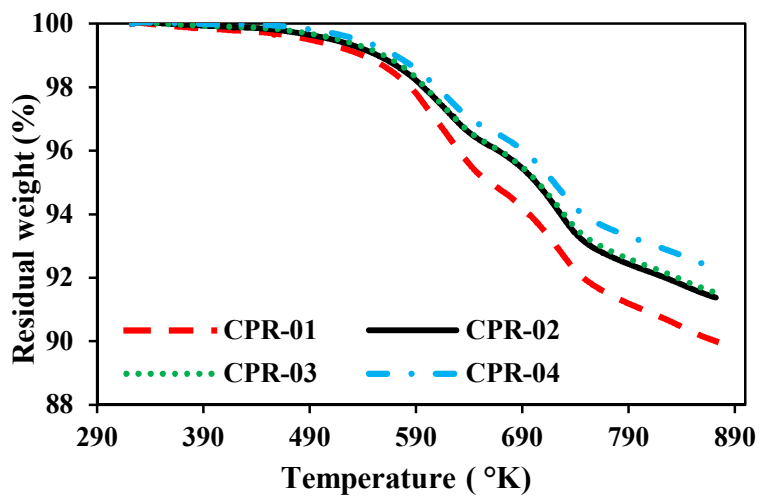

Fig. 4 TGA thermograms of four composite samples

In Fig. 5, CPR-01 has two exothermic peaks at $586.30^{\circ} \mathrm{K}$ and $751.03{ }^{\circ} \mathrm{K}$, and enthalpies of $8.66 \mathrm{~J} / \mathrm{g}$, and $24.16 \mathrm{~J} / \mathrm{g}$, respectively. CPR-02 also has two exothermic peaks at $582.75^{\circ} \mathrm{K}$ and $755.50{ }^{\circ} \mathrm{K}$ and enthalpies of $6.68 \mathrm{~J} / \mathrm{g}$ and $28.05 \mathrm{~J} / \mathrm{g}$, respectively. CPR03/CPR-0 4 have exothermic peaks at $761.38^{\circ} \mathrm{K}$, and $786.38^{\circ} \mathrm{K}$ and enthalpies of $56.25 \mathrm{~J} / \mathrm{g}$ and $1.41 \mathrm{~J} / \mathrm{g}$, respectively. The exothermic peaks of all the samples, when they are associated with the TGA thermogram in Fig. 4, show the weight loss due to the thermal degradation of resin binder and other organic ingredients, such as friction dust, cellulose, and PAN fibers.

Table 2 DSC test results

\begin{tabular}{|c|c|c|c|}
\hline $\begin{array}{c}\text { Sample } \\
\text { code }\end{array}$ & $\begin{array}{c}\text { Maximum } \\
\text { exothermic } \\
\text { peak } \\
\left({ }^{\circ} \mathrm{K}\right)\end{array}$ & $\begin{array}{c}\text { Enthalpy } \\
(\mathrm{J} / \mathrm{g})\end{array}$ & $\begin{array}{c}\text { Peak } \\
\text { width } \\
\left({ }^{\circ} \mathrm{K}\right)\end{array}$ \\
\hline \hline CPR-01 & 751.03 & 24.16 & 24.63 \\
\hline CPR-02 & 755.50 & 28.05 & 45.26 \\
\hline CPR-03 & 761.38 & 56.25 & 56.26 \\
\hline CPR-04 & 786.38 & 1.41 & 9.18 \\
\hline
\end{tabular}

In Table 2, the maximum exothermic peak increases as the content of rockwool fiber increases ( 6 vol. $\%$ to 12 vol. $\%$ ) combined with 4 vol.\% cellulose fiber and the content of PAN fiber decreases $(8$ vol.\% to 2 vol.\%). The enthalpy and the peak width exothermic of samples also increase with the increasing content of rockwool fiber (6 vol.\% to 10 vol.\%) combined with 4 vol.\% cellulose fiber and PAN fiber decreases ( 8 vol. $\%$ to 4 vol.\%). However, the enthalpy and the exothermic peak width of CPR-04 (addition 12 vol.\% rockwool fiber combined with 4 vol.\% cellulose fiber and 2 vol.\% PAN fiber) tend to decrease. In general, these results indicate that an increase in rockwool fiber content requires a higher temperature to release thermal energy as long as the sample is degraded. This phenomenon occurs because the higher rockwool fiber content in the sample tends to have better thermal stability, as seen in the TGA results in Fig. 4. Subsequently, the amount of heat energy (enthalpy) released also increases, except that in CPR-04. The decreasing enthalpy in CPR-04 may be due to the formation of agglomerated rockwool fiber and its non-uniform distribution in resin binder, as seen in Fig. 3. This fiber agglomeration causes the reduction of the crosslinking density of phenolic resin during postcuring. The decreasing crosslinking density of phenolic resin weakens the integrity of the sample at high temperatures ${ }^{(23)}$, Thus, the amount of heat energy (enthalpy) released decreases during the DSC test. This condition also increases the wear of CPR-04.

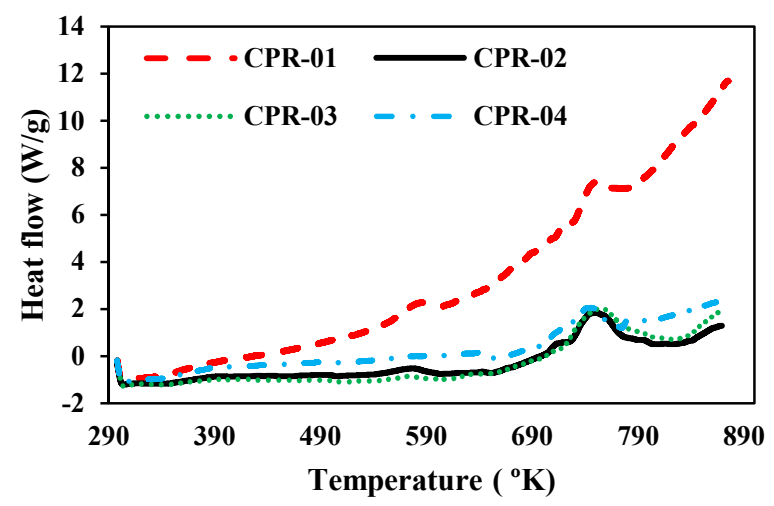

Fig. 5 DSC thermograms of four composite samples

3.3. Friction performance of the composite samples under faderecovery condition

The friction test results of the composite samples under the fade and recovery conditions are presented in Fig. 6. In the fade-1 condition, the friction coefficient of CPR-01/CPR-02 tends to decrease as temperature increases from $365{ }^{\circ} \mathrm{K}$ to $562{ }^{\circ} \mathrm{K}$. Subsequently, the friction coefficient of CPR-03/CPR-04 increases as temperature increases up to $450^{\circ} \mathrm{K}$ and then decreases above this temperature. The decreasing friction coefficient in temperature below $573{ }^{\circ} \mathrm{K}$ is related to the glass transition temperature of phenolic resin in the temperature range of $473{ }^{\circ} \mathrm{K}$ to $573{ }^{\circ} \mathrm{K}{ }^{(24)}$. During transition, phenolic resin softening weakens the bond strength between resin and other ingredients ${ }^{(25)}$, mainly organic ingredients (i.e. friction dust, graphite, cellulose, and PAN fibers in the present study). Therefore, the ingredient of the samples easily detaches from resin binder, the friction coefficient and friction force are reduced ${ }^{(26)}$. Meanwhile, the friction coefficient increases as temperature increases (as in the case of CPR-03/CPR-04) because of the wear debris trapped in the friction interface, which acts as an abrasive in the form of third-body abrasion (TBA) (27). This condition is supported by the higher content of rockwool fiber (10 vol.\% to 12 vol.\%) in CPR-03/CPR-04.

Under the recovery-1 condition, the friction coefficient of CPR-01/CPR-02/CPR-03 increases as the temperature decreases from $533^{\circ} \mathrm{K}$ to $421{ }^{\circ} \mathrm{K}$; thereafter, its friction coefficient decreases below the temperature of $421^{\circ} \mathrm{K}$, except that of CPR-01. CPR-04 shows a different trend, that is its friction coefficient decreases from $477{ }^{\circ} \mathrm{K}$ to $365^{\circ} \mathrm{K}$. Satapathy and Bijwe ${ }^{(8)}$ reported that the increased friction coefficient under a recovery test depends on tribofilms formed after a fade test. The existence of a combination of organic fibers, namely: cellulose and PAN fibers ( 8 vol.\% to 12 vol.\%) in CPR-01/CPR-02/CPR-03 may contribute to the formation of tribofilms on the friction surface after the fade- 1 test is complete. During the recovery- 1 test, the increased temperature on the friction surface is reduced by using an air blower. The cooling process and the intensity of the repeated braking cause a decrease in tribofilms deformability. Thus, the elasticity of the tribofilm is reduced and prone to disintegration. Disintegrated tribofilms generate wear debris and act as abrasives. As such, the friction coefficient of CPR-01/CPR-02/CPR-03 increases during 


\section{Putri Nawangsari et al / International Journal of Automotive Engineering}

Vol.11, No.2(2020)

the recovery-1 test. On the contrary, the decreasing friction coefficient at low temperatures is due to the rheological change in the wear debris at the topography of the contact area of the friction interface (28).

Under the fade- 2 condition, the friction coefficient of CPR01/CPR-03 increases as temperature rises up to $422^{\circ} \mathrm{K} / 450^{\circ} \mathrm{K}$ and then decreases above this temperature. On the contrary, the friction coefficient of CPR-02 decreases as temperature increases up to 478 ${ }^{\mathrm{o}} \mathrm{K}$ and then increases above this temperature. Meanwhile, the friction coefficient of CPR-04 decreases as temperature increases up to $618^{\circ} \mathrm{K}$. The decreasing friction coefficient with a temperature increase of up to $618{ }^{\circ} \mathrm{K}$ is related to the weakening of the bond strength and the softening of phenolic resin in the range of glass transition temperature and thermal decomposition. A higher proportion of rockwool fiber agglomeration in CPR-04 promotes the decrease in the crosslinking density of the phenolic resin. As a result, the bond strength between phenolic resin and rockwool fiber weakens at elevated temperatures and the friction coefficient decreases. Meanwhile, the increasing friction coefficient with an increase in temperature as in the case of CPR-01/CPR-02/CPR-03 is related to the wear debris trapped in the friction interface, which acts as a TBA ${ }^{(27)}$.

During the recovery-2 test (Fig. 6), the friction coefficient of CPR-01 decreases as temperature decreases from $589^{\circ} \mathrm{K}$ to $365^{\circ} \mathrm{K}$. The friction coefficient of CPR-02/CPR-03/CPR-04 increases in the temperature range of $589{ }^{\circ} \mathrm{K}$ to $533{ }^{\circ} \mathrm{K}$ and then gradually decreases as temperature decreases from $533{ }^{\circ} \mathrm{K}$ to $365^{\circ} \mathrm{K}$. In a previous discussion on the recovery- 1 test, the revival of the friction coefficient depends on the formation of tribofilms during the fade condition. The higher proportion of rockwool fiber (8 vol. $\%$ to 10 vol. $\%$ ) combined with 4 vol. $\%$ cellulose fiber and PAN fiber decreases ( 6 vol. $\%$ to 4 vol. $\%$ ) causes the wear debris to be trapped in the friction interface acting as TBA. This phenomenon may be a possible reason for the increase in the friction coefficient at the initial recovery-2 of CPR-02/CPR-03/CPR-04. Subsequently, the reduction of the friction coefficient with a decrease in temperature is due to rheological alteration at the contact area topography in the friction interface ${ }^{(\mathbf{2 8})}$.

\subsubsection{CoF performance ( $\mu$ p) and $\mathrm{CoF}$ fluctuation $\left(\mu_{\max }-\mu_{\min }\right)$}

Fig. 7 shows the CoF performance ( $\mu$ p) and CoF fluctuation as a function of the sample composition. The $\mathrm{CoF}$ performance ( $\mu$ p) of the four samples ranges from 0.44 to 0.49 . The highest $\mathrm{CoF}$ performance is observed in CPR-03, whereas the lowest CoF performance is found in CPR-02

The CoF fluctuation of the four samples remains low in the range of 0.13 to 0.22 . The CoF fluctuation of the sample decreases as the content of rockwool fiber increases (6 vol.\% to 10 vol.\%) combined with 4 vol. $\%$ cellulose fiber and PAN fiber decreases (8 vol.\% to 4 vol.\%) because of the higher content of inherent metallic-silicates $\left(\mathrm{SiO}_{2}, \mathrm{Al}_{2} \mathrm{O}_{3}, \mathrm{CaO}+\mathrm{MgO}\right.$, and $\left.\mathrm{Fe}_{2} \mathrm{O}_{3}\right)$ in rockwool fiber ${ }^{(29)}$ and these silicates contribute to the thermal stability and CoF stability of the sample ${ }^{(9)}$. Comprehensively, the sample formulation with a high response to $\mathrm{CoF}$ performance shows a low $\mathrm{CoF}$ fluctuation in the friction response. The magnitude of CoF fluctuation should be as low as possible because it effectively minimizes noise, vibration, and judder generated during the braking operation ${ }^{(4)}$.
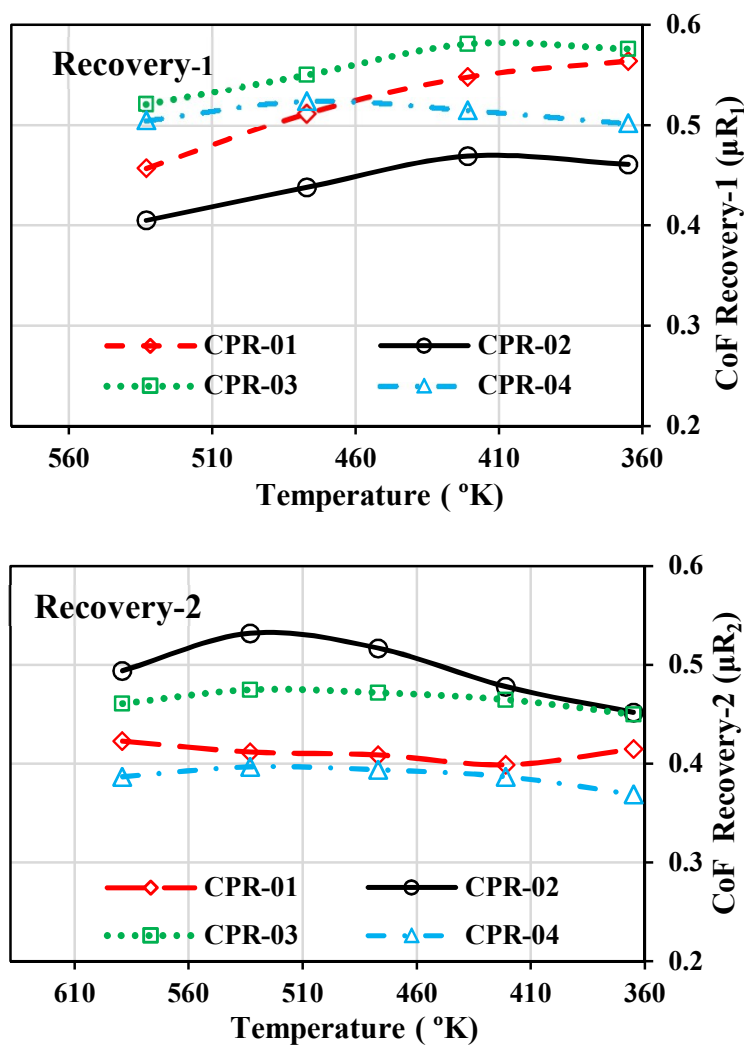

Fig. 6 Friction coefficient test results of the composite samples under fade and recovery condition 


\section{Putri Nawangsari et al / International Journal of Automotive Engineering}

Vol.11, No.2(2020)

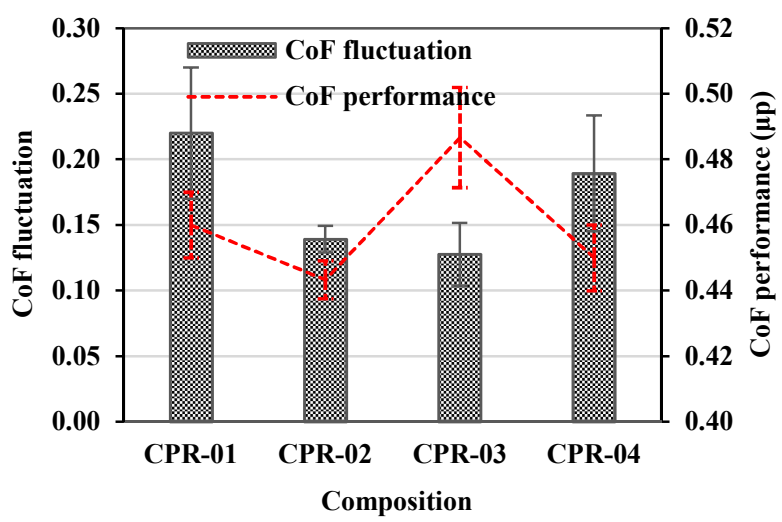

Fig. 7 CoF performance ( $\mu$ p) and CoF fluctuation versus the composition of the composite samples

\subsubsection{CoF stability and variability}

The CoF stability and CoF variability as a function of composition are presented in Fig. 8. The CoF stability of the four samples is in the range of 0.84 to 0.89 . The maximum $\mathrm{CoF}$ stability is observed in CPR-03, whereas the minimum CoF stability is found in CPR-01. Furthermore, the CoF variability of the four samples remains in the range of 0.24 to 0.45 . The maximum $\mathrm{CoF}$ variability is detected in CPR-01, whereas the minimum CoF variability is recorded in CPR-03. In general, these results indicate that the increasing rockwool fiber content (6 vol. $\%$ to 10 vol.\%) combined with 4 vol.\% cellulose fiber and the decreasing PAN fiber ( 8 vol.\% to 4 vol.\%) increase the CoF stability and decrease the CoF variability. These phenomena occur because the high content of rockwool fiber in the sample can reduce heat transfer from the rotating drum to the sample ${ }^{(\mathbf{1 2})}$ due to its better thermal stability, it is supported by TGA results in Fig. 4, which contributes to the enhancement of the $\mathrm{CoF}$ stability and the CoF variability reduction. Normally, CoF stability level must be as high as possible because it contributes smooth braking friction and avoids jerks during the braking operation. Meanwhile, the magnitude of the $\mathrm{CoF}$ variability must be as low as possible to prevent brake failure due to the loss of friction coefficient when brake is suddenly applied (31)(32). Therefore, CPR-03 has maximum CoF stability and minimum $\mathrm{CoF}$ variability that lead to an efficient braking performance.

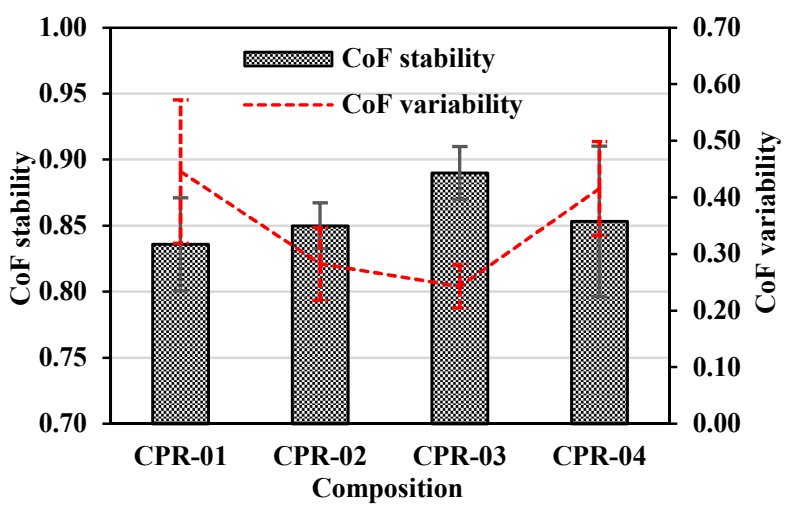

Fig. $8 \mathrm{CoF}$ stability and $\mathrm{CoF}$ variability versus the composition of the composite samples

\subsection{3. \% fade performance and $\%$ recovery performance}

Fig. 9 shows the \% fade performance and the \% recovery performance as a function of the composite sample composition. CPR-01, CPR-02, CPR-03, and CPR-04 have \% fade performance of $25.19 \%, 12.88 \%, 12.36 \%$, and $24.05 \%$ respectively. These results indicate that the $\%$ fade performance decreases as the content of rockwool fiber increases (6 vol.\% to 10 vol.\%) combined with 4 vol. $\%$ cellulose fiber and the content of PAN fiber decreases ( 8 vol. $\%$ to 4 vol. $\%$ ). The $\%$ fade performance of CPR04 (with 12 vol.\% rockwool fiber content combined with 4 vol.\% cellulose fiber and 2 vol.\% PAN fiber) tends to decrease. The decreasing \% fade performance, as seen in CPR-01/CPR-02/CPR03 is related to rockwool fiber content ( 6 vol. $\%$ to 10 vol. $\%$ ) that affects the thermal stability of the sample, as seen in TGA results (Fig. 4). Therefore, it tends to stabilize the thermal in the friction interface at elevated temperatures. Theoretically, rockwool fiber has a low thermal conductivity $(0.04 \mathrm{~W} / \mathrm{mK})$ that affects the decrease in heat transfer on the friction interface from the disc to the pad composite, thereby minimizing friction loss effect (12)(13). Meanwhile, the \% fade performance of the CPR-04 sample increases, even though it has the highest thermal stability. It may be attributed to some fiber agglomerations formed on the CPR-04 sample, as seen in Fig. 3. Fiber agglomeration leads to fiber nonuniformly distributed in the binder resin. It causes the sample more susceptible to structural discontinuities and decreases in the structural integrity of the sample at elevated temperatures during the braking. This condition is a possible reason for an increase in the $\%$ fade performance on the CPR-04 sample.

Normally, the high \% fade performance must be avoided because it tends to cause sudden brake failure. The $\%$ fade performance of the brake friction material is required to be less than $25 \%$ in the temperature range of $573{ }^{\circ} \mathrm{K}$ to $723{ }^{\circ} \mathrm{K}$ for safety braking operation ${ }^{(33)}$. The $\%$ fade performance of four samples shows that CPR-02/CPR-03/CPR-04 is still within the permissible $\%$ fade performance limit.

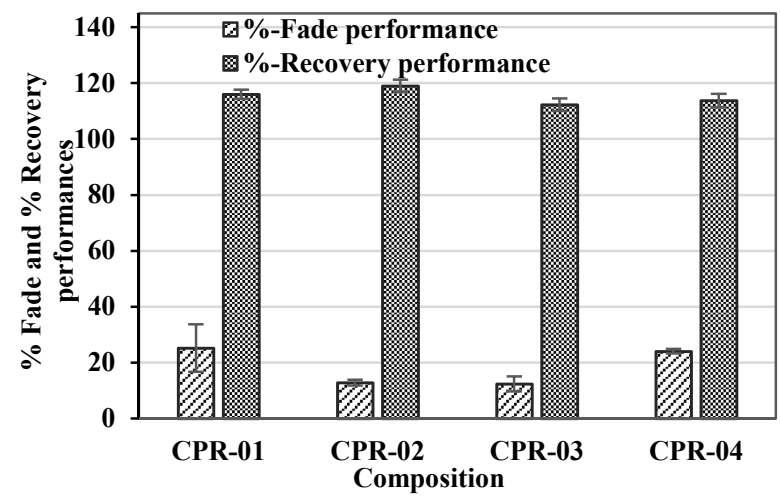

Fig. $9 \%$ fade performance and $\%$ recovery performance versus the composition of the composite samples

The $\%$ recovery performances of all four samples are observed exceed $100 \%$. The $\%$ recovery performance of the sample increases by $2.56 \%$ from CPR-01 to CPR-02 followed by a decrease in the $\%$ recovery performance in CPR-03/CPR-04. Comprehensively, these results indicate that the $\%$ recovery performance of samples 


\section{Putri Nawangsari et al / International Journal of Automotive Engineering}

Vol.11, No.2(2020)

decreases with the increasing content of rockwool fiber (10 vol.\% to 12 vol.\%) combined with 4 vol.\% cellulose fiber, and the decreasing content of PAN fiber ( 4 vol. $\%$ to 2 vol. $\%$ ). This finding is due to the high content of organic fibers i.e. cellulose and PAN fibers in the sample and these fibers dominate the deformation and reformation of tribofilms in the friction interface during the dynamic braking operation (14). In general, the \% recovery performance is in the range of $100 \%$ to $120 \%$ for a good brake pad material ${ }^{(34)}$ and the higher value is better. A high \% recovery performance indicates that the brake pad cools rapidly and returns to the pre fade friction coefficient level. Thus, all the samples show a fast recovery condition.

\subsection{Wear of the composite sample}

The wear of the samples is obtained from the weight loss and the thickness loss after the friction test. The wear of the four samples is presented in Fig. 10. These graphs show that the weight loss and the thickness loss of the samples decrease as the content of rockwool fiber increases ( 6 vol.\% to 10 vol.\%) combined with 4 vol. $\%$ cellulose fiber and the content of PAN fiber decreases $(8$ vol. $\%$ to 4 vol.\%). However, the wear loss of CPR-04 (with added 12 vol.\% rockwool, 4 vol.\% cellulose, and 2 vol.\% PAN fibers) increases. In general, these wear results follow this trend: CPR-04 $>$ CPR-01 > CPR-03 > CPR-02. The decreasing wear from CPR01 to CPR-03 is associated with a synergic combination between rockwool, cellulose, and PAN fibers in the sample, thereby contributing to the formation of topographic features, i.e. primary and secondary contact plateaus. Therefore, they help reduce the wear of the sample, as evidenced in the worn surface of the samples in Figs. 11a to $11 \mathrm{c}$. Weitao et al. ${ }^{(3)}$ also reported that the wear resistance of a friction material is affected by the formation of tribofilms on the friction surface. Tribo film formation is based on the accumulation and compaction of wear debris, i.e. fibers and particles in the interstices of surface asperities ${ }^{(35)(36) .}$

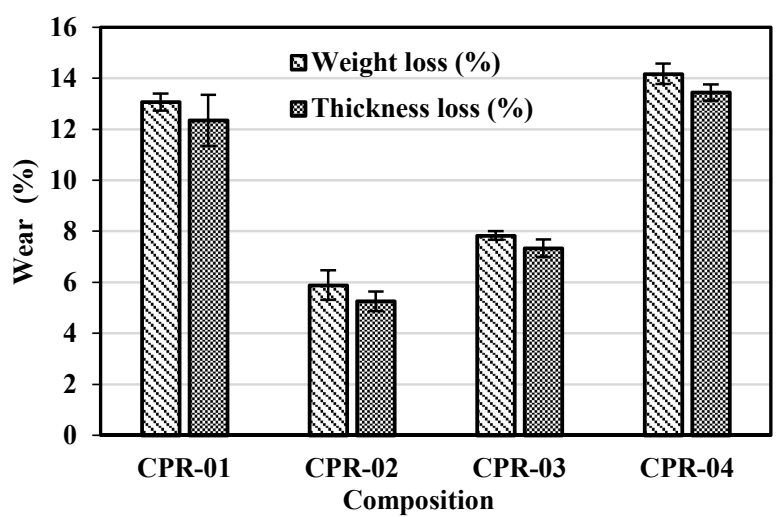

Fig. 10 Wear versus the composition of the composite samples

The lowest wear is shown in CPR-02. Meanwhile, the highest wear observed in CPR-04 despite its better thermal stability. It is related to the presence of high rockwool fiber content (12 vol.\%) in the sample. As such, natural abrasive elements in rockwool fiber dominate the abrasive wear mechanism during the braking process. Structural discontinuities or decreased sample integrity due to fiber agglomeration can also be a major factor in the excessive wear loss of CPR-04. It can be confirmed from the worn surface of the CPR04, as shown in Fig. 11d.

\subsection{Surface morphology of sample wear}

Fig. 11 shows the worn surface morphology of the four samples after the friction test. Their worn surface morphology represents different characteristics of secondary/primary plateau formation, secondary flake formation, and subsurface damage, which can be related to the wear mechanism and responsible for the wear of the sample.

Fig. 11a exhibits the worn surface of CPR-01. Few secondary flakes are formed. On the higher magnification view, the wear debris is widely dispersed on the surface and the backside area of the delaminated secondary plateau. The backside area of the delaminated secondary plateau may be caused by poor adhesive contact in the friction interface, as a result of degradation of organic ingredients at elevated temperatures. The area worn surface of CPR-01 in a higher magnification view was analyzed using EDS (Energy Dispersive Spectroscopy), as in Figure 12a. The analysis shows that the elements were detected in this area i.e., carbon $(\mathrm{C})$, oxygen $(\mathrm{O})$, aluminum $(\mathrm{Al})$, silicon $(\mathrm{Si})$, calcium $(\mathrm{Ca})$, sulfur $(\mathrm{S})$, iron $(\mathrm{Fe})$, copper $(\mathrm{Cu})$, and barium $(\mathrm{Ba})$. These elements are mostly originated from the sample ingredients and the higher concentration is revealed in element $\mathrm{C}(32.69 \%)$ and $\mathrm{O}(30.35 \%)$. It indicates that the organic ingredients of CPR-01 (namely, friction dust, phenolic resin, graphite, cellulose, and PAN fibers) are thermally oxidized and carbonized to producing carbon phase. Subsequently, the carbon phase is transferred to the worn surface of the sample as thin carbon layers due to the shear force and friction heat, simultaneously. The EDS analysis results of all samples in Fig. 12 shows that CPR-01 has a higher concentration of carbon element to the other samples. It is associated with a higher proportion of 12 vol.\% organic fibers (cellulose and PAN) combined with 6 vol.\% rockwool fiber in the CPR- 01 .

The worn surface of CPR-02 is presented in Fig. 11b. The secondary contact plateaus form on the worn surface of CPR-02, and few subsurface damages are seen. At the magnified view, several microcracks and pits filled with wear debris were found on the surface secondary contact plateau. According to previous literature studies ${ }^{(29)(10)(35)}$, the formation of secondary contact plateaus is dominated by the accumulation of compacted debris on the surface of primary contact plateau as a result of shear force, normal force, and friction heat, simultaneously. Based on the EDS analysis results in Fig. $12 \mathrm{~b}$ reveals that the secondary contact plateau in the CPR-02 formed by compacted debris from the elements of the ingredient sample, such as $\mathrm{C}, \mathrm{O}, \mathrm{Mg}, \mathrm{Al}, \mathrm{Si}, \mathrm{S}, \mathrm{Ca}$, $\mathrm{Fe}, \mathrm{Cu}, \mathrm{Ba}$. Among these elements, $\mathrm{Fe}$ and $\mathrm{O}$ show a higher concentration, with their concentration are $31.82 \%$ and $32.83 \%$, respectively. Fe and $\mathrm{O}$ elements were detected in the EDS analysis due to the elements inherent in rockwool fiber ${ }^{(29)}$. Besides, the presence of $\mathrm{Fe}$ and $\mathrm{O}$ was possibly transferred from drum disc material (cast iron) to worn surface sample as a result of the friction thermal-induced oxidation (tribo-oxidation) during friction test, in agreement with previous literature study results ${ }^{(37)(38) .}$ The tribooxidation occurring on the surface drum disc rubbing against the sample caused transfer film develops well on the sample surface of CPR-02. The synergistic combination of organic fiber, i.e., cellulose and PAN fibers (10 vol.\%) combined with 8 vol.\% 


\section{Putri Nawangsari et al / International Journal of Automotive Engineering}

Vol.11, No.2(2020)

rockwool fiber contributes to facilitating the formation of uniform film transfers on the sample to the drum disc surface. This condition causes the worn surface CPR-02 covered by a smooth and compact secondary contact plateau, which is responsible for the lowest wear of CPR-02. Meanwhile, microcracks form on the secondary plateau surface because of thermal shock stresses (3). Generally, an increase in friction causes an increase in temperature in the friction interface ${ }^{(39)}$. The friction interface is exposed to

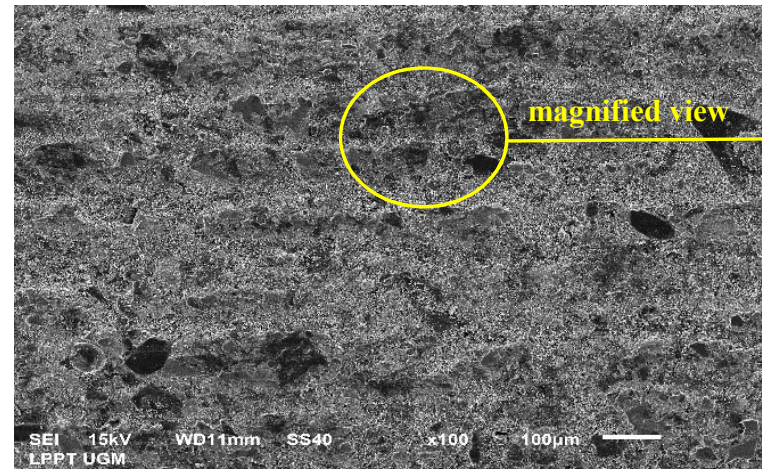

friction heat and load pressure, which generates an unstable temperature and a difference in thermal expansion on various zones of the friction interface ${ }^{(40)}$. This condition results in thermal stress microcracks on the worn surface of CPR-02. Subsequently, the area nearby the cracks is easily detached during the friction. It leads to the formation of flake pits under intense shear stress and the simultaneous extension of the braking time.

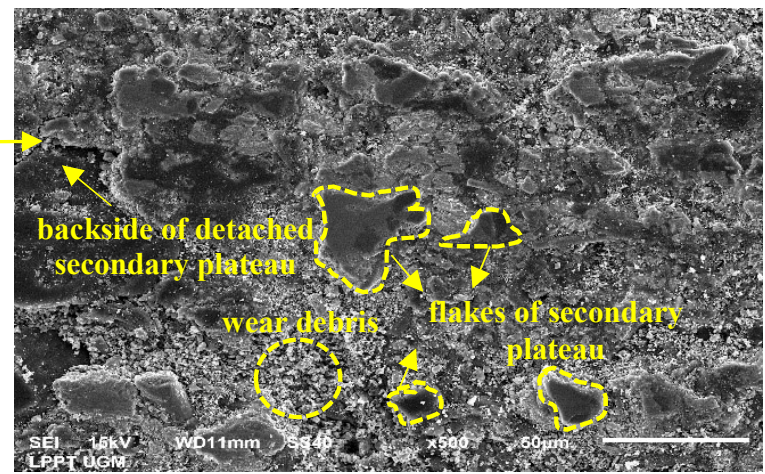

(a)
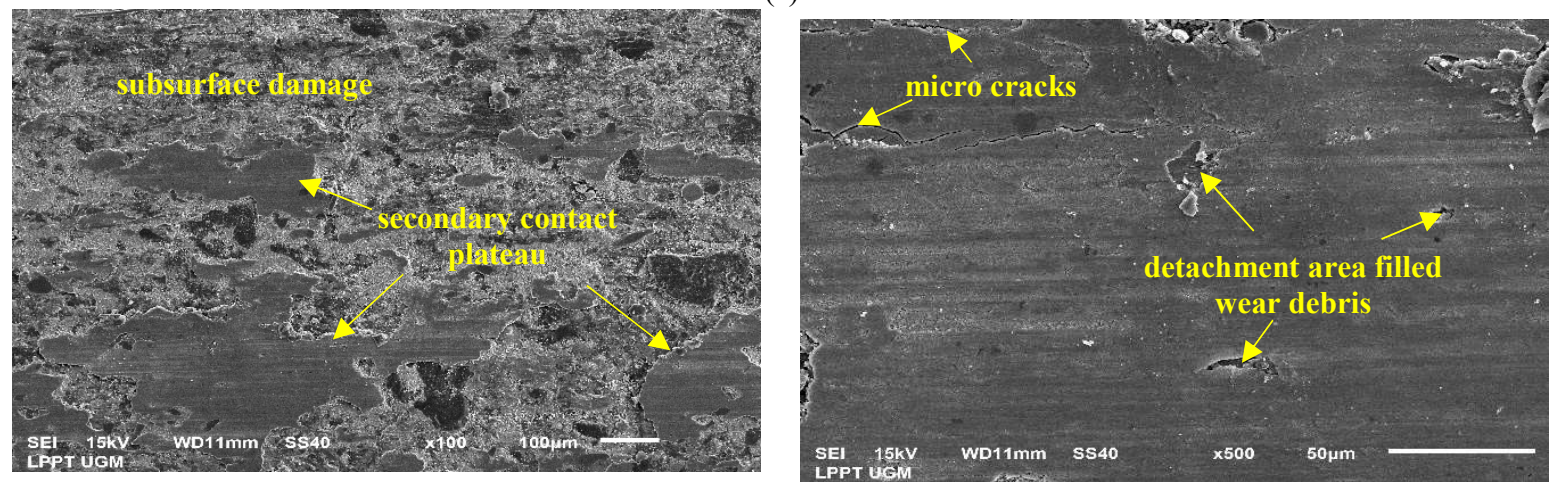

(b)
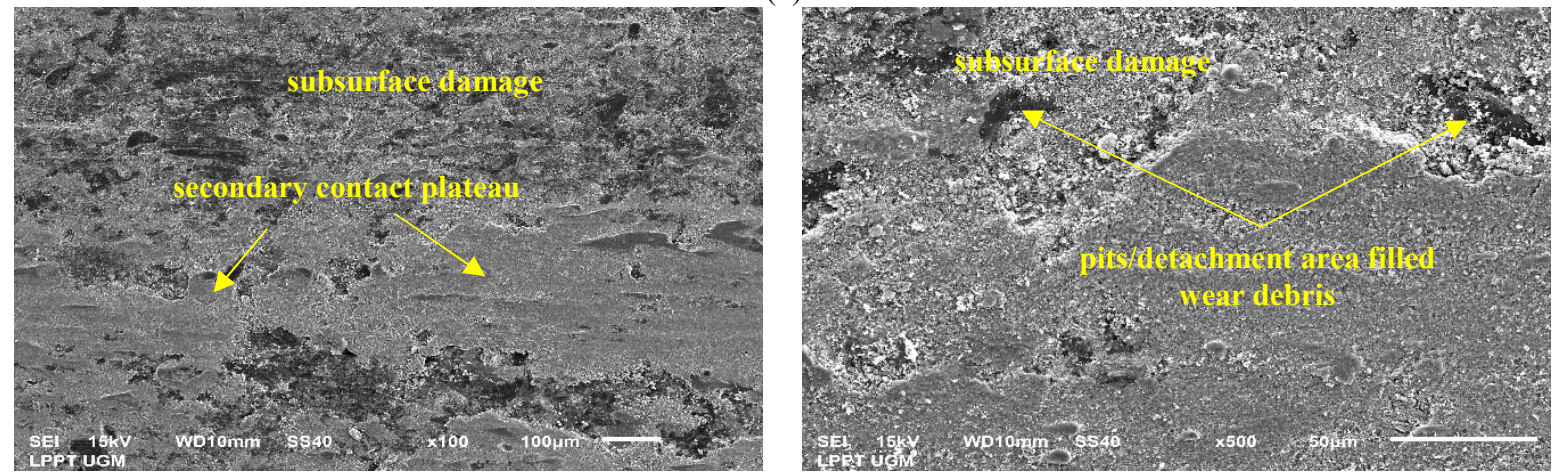

(c)
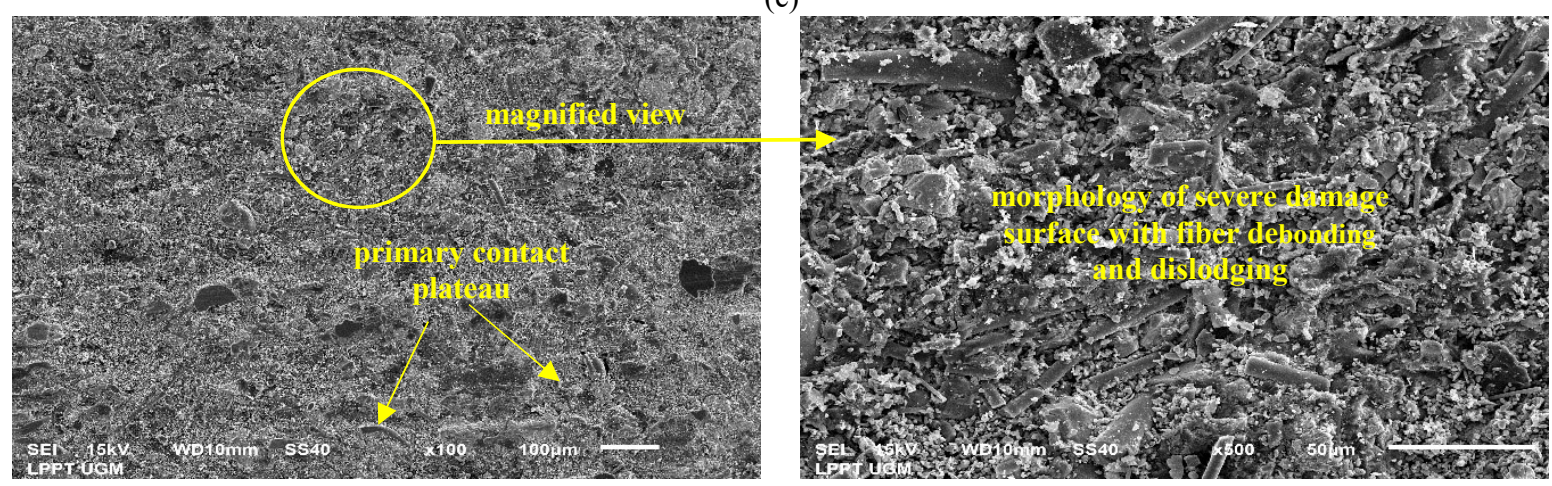

(d)

Fig. 11 Surface morphology of sample wear: (a) CPR-01, (b) CPR-02, (c) CPR-03, and (d) CPR-04 


\section{Putri Nawangsari et al / International Journal of Automotive Engineering}

Vol.11, No.2(2020)

The worn surface of CPR-03 is presented in Fig. 11c. The secondary contact plateau form on the worn surface with subsurface damage on the bulk sample. At a magnified view, it is seen the secondary contact plateau is not compacting well and is several visible pits (detached area) nearby area of the secondary contact plateau. This secondary contact plateau is mainly composed of Fe element (49.92\%) and $\mathrm{O}$ (28.44\%), as shown from the EDS analysis results in Fig.12c. Other elements in the ingredients of the sample are also detected, although their concentration is lower. As a previous discussion in the worn surface of CPR-02 that $\mathrm{Fe}$ and $\mathrm{O}$ elements are originated from an inherent constituent in rockwool fiber and the tribo-oxidation of drum disc. However, the concentration of Fe element in the worn surface of CPR-03 is relatively higher than that of CPR-02. It indicates that CPR-03 is more actively abrasion of the surface of the drum disc.

The combination of 10 vol $\%$ rockwool, 4 vol. $\%$ cellulose, and 4 vol.\% PAN fibers in CPR-03 is unable to form uniform transfer film on the drum disc surface and is not capable of creating sufficient compact secondary contact plateau. Thereby, the wear of CPR-03 is higher than CPR-02.

Meanwhile, pits formation (detached area) on the worn surface of CPR-03 may be attributed to the dislodging of hard ingredients, namely: rockwool fiber, $\mathrm{SiO}_{2}, \mathrm{Al}_{2} \mathrm{O}_{3}$, and $\mathrm{BaSO}_{4}$ from the surface. This condition is caused by weakening in a particular area due to local softening as a result of the thermal shear stress ${ }^{(29)}$, which is responsible for subsurface damage.

The worn surface of CPR-04 in Fig.11d is visible as a severe damage surface by showing a large amount of wear debris, which

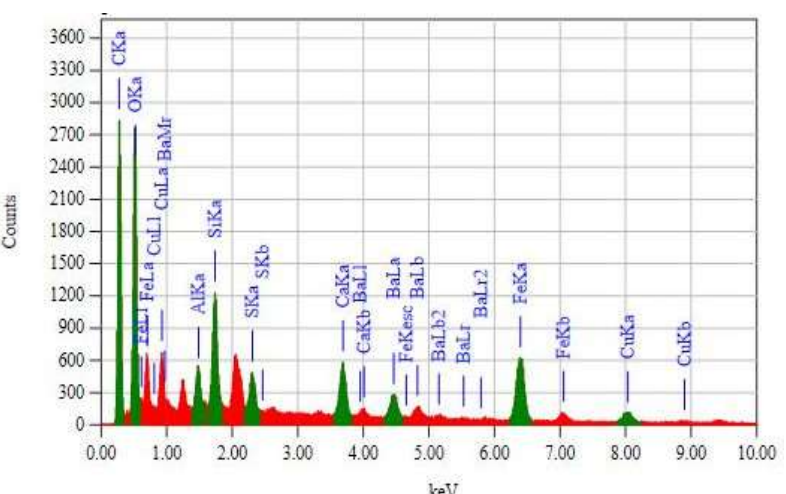

(a)

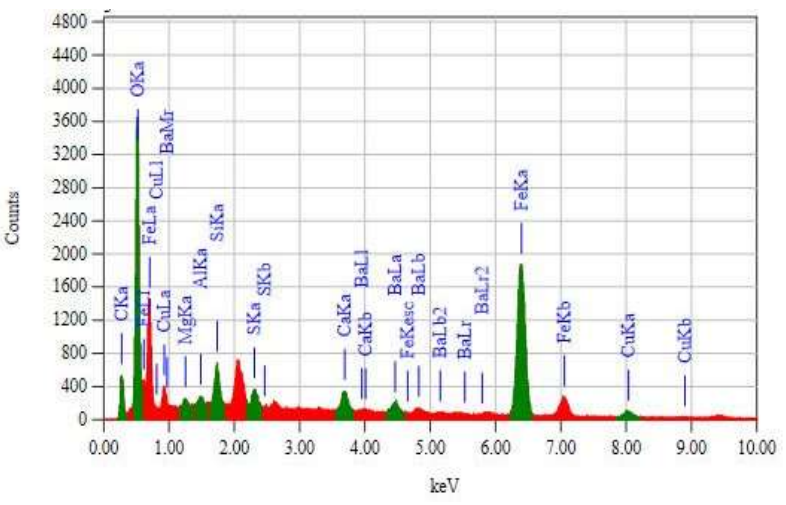

(c) is scattered evenly on its worn surface. Besides, fiber debonding and fiber fracture are also visible.

The result of the EDS analysis in Figure.12d shows that the worn surface area is formed by elements $\mathrm{C}, \mathrm{O}, \mathrm{Mg}, \mathrm{Al}, \mathrm{Si}, \mathrm{S}, \mathrm{Ca}$, $\mathrm{Fe}, \mathrm{Cu}$, and $\mathrm{Ba}$. The elements $\mathrm{C}$ and $\mathrm{O}$ show a higher concentration than the other element with their concentration are $25.74 \%$ and $27.66 \%$, respectively. It indicates that the area occurs thermaloxidized and carbonized. The presence of 12 vol.\% rockwool fiber in CPR-04 prevents the uniform dispersion of the fiber in the resin binder, as a result of fiber agglomeration. Fiber agglomeration easily detaches from resin binder at high temperature and shear stress simultaneously. This phenomenon causes damage to fiber acts as TBA together with other hard ingredients. TBA leads to an abrasive wear mechanism ${ }^{(41)}$ responsible for the severe damage and poor wear performance of CPR-04.

Abrasive wear mechanism due to non-uniformly dispersed fiber in the matrix was also reported by Yunhai Ma et al. ${ }^{(5)}$. They concluded that non-uniformly dispersed fibers in a matrix cause poor cohesive strength between fibers and the matrix, thereby producing several hard asperities, wear debris, and severe damage when the matrix surface subjected to frictional force at a high temperature. Tayeb et al. (10) also reported that a weak cohesive strength between fibers and resin binder leads to severe wear on composite fiber reinforcements.

The existence of a combination of fiber reinforcement (rockwool, cellulose, and PAN) in the sample has a systematic effect on the formation-reformation-destruction mechanism of contact plateaus, which control the tribological response of the samples under friction braking conditions.

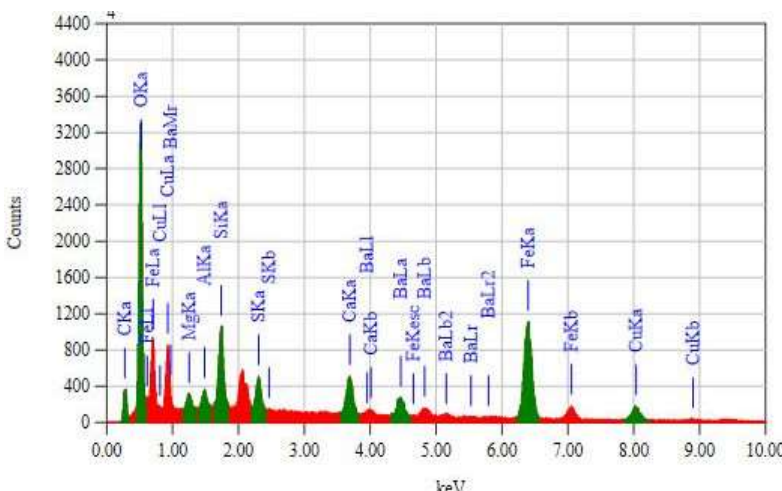

(b)

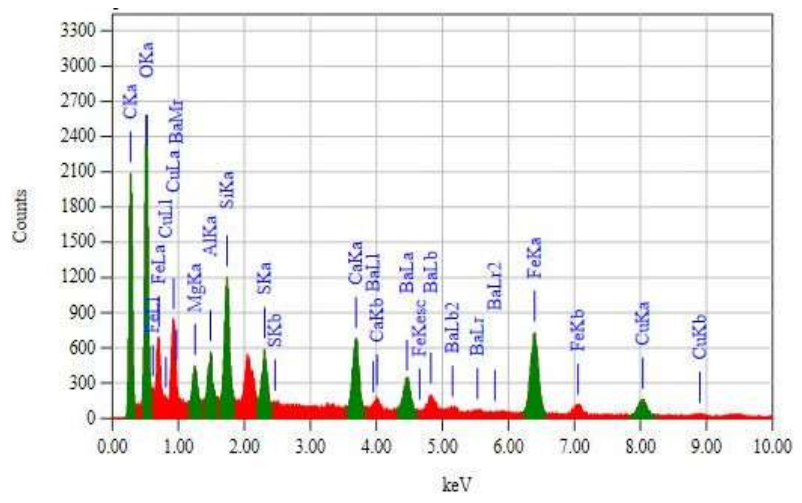

(d)

Fig. 12 EDS analysis on the worn surface sample: (a) CPR-01, (b) CPR-02, (c) CPR-03, and (d) CPR-04 


\section{Putri Nawangsari et al / International Journal of Automotive Engineering}

Vol.11, No.2(2020)

\section{Conclusions}

In this experimental study, a NAO brake pad composite based on ternary fiber reinforcements (rockwool-PAN-cellulose) were fabricated and its thermal properties and tribological properties was characterized under fade-recovery conditions. The performance of tribological properties was assessed in terms of coefficient of friction $(\mathrm{CoF})$ performance, $\mathrm{CoF}$ fluctuation, $\mathrm{CoF}$ stability and variability, $\%$ fade performance, $\%$ recovery performance, and wear. The comprehensive conclusions are summarized as follows:

1. The thermal stability of the sample increases as the content of rockwool fiber increases combined with 4 vol.\% cellulose fiber and the content of PAN fiber decreases.

2. The sample with 10 vol.\% rockwool fiber combined with 4 vol.\% cellulose fiber, and 4 vol.\% PAN fiber exhibits the highest CoF performance.

3. The CoF fluctuation and CoF variability of the sample decrease when the content of rockwool fiber increases ( 6 vol.\% to 10 vol.\%) combined with 4 vol. $\%$ cellulose fiber and the content of PAN fiber decreases ( 8 vol. $\%$ to 4 vol. $\%$ ). On the contrary, CoF stability increases

4. As the content of rockwool fiber increases (6 vol.\% to 12 vol.\%) combined with 4 vol. $\%$ cellulose fiber and the content of PAN fiber decreases ( 8 vol. $\%$ to 2 vol. $\%$ ), $\%$ fade performance of the sample improves. The addition of $10 \mathrm{vol} . \%$ rockwool fiber combined with 4 vol.\% cellulose fiber and 4 vol.\% PAN fiber, i.e., the CPR-03 sample shows the lowest \% fade performance.

$\%$ recovery performance of the sample decreases as the content of rockwool fiber decreases combined with 4 vol.\% cellulose fiber and the content of PAN fiber increases, except for CPR02 .

5. The wear resistance increase as the content of rockwool fiber increases (6 vol.\% to 10 vol.\% ) combined with 4 vol.\% cellulose fiber and the content of PAN fiber decreases ( 8 vol.\% to 4 vol.\%).

Comprehensively, an increase in the content of rockwool fiber ( 6 vol. $\%$ to 10 vol. $\%$ ) combined with 4 . vol. $\%$ cellulose fiber and a decrease in the content of PAN fiber ( 8 vol.\% to 4 vol. $\%$ ) are effective in increasing the thermal stability and CoF stability, improves $\%$ fade performance of the sample. However, $\%$ recovery performance, $\mathrm{CoF}$ fluctuations, and $\mathrm{CoF}$ variability of the sample decrease. Therefore, the CPR-03 sample with a synergistic combination of 10:4:4 vol.\% rockwool, cellulose, and PAN fibers exhibited the best overall friction performance under fade-recovery conditions.

\section{Acknowledgments}

This research is supported by Ph.D. Grant of Endowment Fund for the Education (LPDP) Ministry of Finance Republic Indonesia under the contract number PRJ-1436/LPDP.4/2019.

\section{References}

(1) Sundarkrishnaa, K. L., "Friction Material Composites", Springer Series in Materials Science. 171 (2013).

(2) Hamid, A., Lazim, M., Bakar, A., "Brake Wear Particle Size and Shape Analysis of Non-Asbestos Organic ( NAO ) and Semi Metallic Brake Pad". Jurnal Teknologi, 71:2 (2014) 129-34.

(3) Sun, W., Zhou, W., Liu, J., Fu, X., Chen, G., Yao, S,. "Development of a Composite Friction Material with Excellent Fade Resistance by Employing Oversized Ceramic Particles", Tribol Lett. 66:22 (2018) 1-11.

(4) Singh, T., "Assessment of Braking Performance of LapinusWollastonite Fibre Reinforced Friction Composite Materials", Journal King Saud Univ - Eng Sci. 29:2 (2015) 183-190.

(5) Ma, Y., Liu, Y., Wang, L., Tong, J., Zhuang, J., Jia, H., "Performance Assessment of Hybrid Fibers Reinforced Friction Composites under Dry Sliding Conditions", Tribology International. 119 (2018) 262-9.

(6) Liew, K.W., Nirmal, U., "Frictional Performance Evaluation of Newly Designed Brake Pad Materials", Materials and Design. 48 (2013) 25-33.

(7) Akıncioglu, G., Oktem, H., Uygur, I., Akincioglu, S., "Determination of Friction-Wear Performance and Properties of Eco-Friendly Brake Pads Reinforced with Hazelnut Shell and Boron Dusts", Arab. J. Sci Eng. 43:4 (2018) 4727-4737.

(8) Satapathy, B. K., J. Bijwe. "Fade and Recovery Behavior of Non-asbestos Organic (NAO) Composite Friction Materials based on Combinations of Rock Fibers and Organic Fibers", J Reinf Plast Compos.24:6 (2005) 563-577.

(9) Patnaik, A., Kumar, M., Satapathy, B. K., Tomar, B. S., "Performance Sensitivity of Hybrid Phenolic Composites in Friction Braking: Effect of Ceramic and Aramid Fibre Combination", Wear. 269:12 (2010) 891-899.

(10) Taylor, P., Öztürk, B., Arslan, F., Öztürk, S. "Effects of Different Kinds of Fibers on Mechanical and Tribological Properties of Brake Friction Materials Effects of Different Kinds of Fibers on Mechanical and Tribological Properties of Brake Friction Materials", Tribol Trans. 56:4 (2013) 3741.

(11) Jang, H., Lee, J. S., Fash, J. W, "Compositional Effects of the Brake Friction Material on Creep Groan Phenomena", Wear. 250: 251 (2001) 1477-1483.

(12) Stephen, B,. Jayakumari, L. S., "Effect of Rockwool and Steel Fiber on the Friction Performance of Brake Lining Materials", Rev Mater. $21: 3$ (2016) 656-665.

(13) Liu, Y., Ma, Y., Xueman, J., Yu, J., Zhuang, J., and Tong, J., "Mineral Fibre Reinforced Friction Composites: Effect of Rockwool Fibre on Mechanical and Tribological Behaviour", Mat. Research Express. 5:9 (2018) 1-18.

(14) Satapathy, B. K, Bijwe, J., "Performance of Friction Materials based on Variation in Nature of Organic Fibres Part I . Fade and Recovery Behaviour". Wear, 257 (2004) 573584.

(15) Ho, S.C., Lin, J. H. C., Ju, C.P,. "Effect of Fiber Addition on Mechanical and Tribological Properties of a Copper/ Phenolic-Based Friction Material", Wear. 258:1 (2005) 861- 


\section{Putri Nawangsari et al / International Journal of Automotive Engineering}

Vol.11, No.2(2020)

869.

(16) Nawangsari, P., Jamasri, Rochardjo, H. S. B., Waskito, A. T., "BaSO 4 -Friction Dust Filler Improves Friction Characteristic in Non-Asbestos Brake Pad Composite", Int Rev Mech Eng.13:9 (2019) 513-522.

(17) Chen, C. W. S,. "Factors Influencing Particle Agglomeration During Solid-State Sintering", Acta. Mech. Sin. 28:3 (2012) 711-719.

(18) Santos, R. M., Mould, S. T., Form, P., Paiva, M. C,. "Effects of Particle Size and Surface Chemistry on the Dispersion of Graphite Nanoplates in Polypropylene Composites", Polymer. 10:22 (2018) 1-14.

(19) Shakerau Yakubu, A., Danjuma Saleh, Y., "Evaluation of the Wear and Thermal Properties of Asbestos Free Brake Pad using Periwinkles Shell Particles", Usak Univ J Mater Sci. 1 (2013) 99-108.

(20) Wang, F., Huang, Z., Zhang, G,. "Preparation and Thermal Stability of Heat-Resistant Phenolic Resin System Constructed by Multiple Heat-Resistant Compositions Containing Boron and Silicon", High Perform Polym. 29: 4 (2017) 493-498.

(21) Torre, J. M. K., Maffezzoli, A. M., "Degradation Behaviour of a Composite Material for Thermal Protection Systems Part I - Experimental Characterization", J Mater Sci. 3 (1998) 3137-3143.

(22) Yliniemi, J., Kinnunen, P., Karinkanta, P., Illikainen, M., Utilization of Mineral Wools as Alkali-Activated Material Precursor. Materials. 9 (2016) 1-12.

(23) Ahmadijokani, F., Shojaei, A., Arjmand, M., Alaei, Y., Yan, N., "Effect of Short Carbon Fiber on Thermal, Mechanical and Tribological Behavior of Phenolic-based Brake Friction Materials", Compos Part B. 68 (2019) 98-105.

(24) Kim, Y. C., Cho, M. H., Kim, S. J., Jang. H., "The Effect of Phenolic Resin, Potassium Titanate, and CNSL on the Tribological Properties of Brake Friction Materials", Wear. 264:3 (2008) 204-210.

(25) Cho, K. H., Cho, M. H., Kim, S. J., Jang. H., "Tribological Properties of Potassium Titanate in the Brake Friction Material; Morphological Effects", Tribol Lett. 32:1 (2008) 59-66.

(26) Ji, Z., Luo, W., Zhou, K., Hou, S., Zhang, Q., Li, J., "Effects of the Shapes and Dimensions of Mullite Whisker on the Friction and Wear Behaviors of Resin-Based Friction Materials", Wear. 406-407 (2018) 118-25.

(27) Liu Y, Xie J, Wu N, Wang L, Ma Y, Tong J. Tribology International In $\mathrm{fl}$ uence of silane treatment on the mechanical, tribological and morphological properties of corn stalk fi ber reinforced polymer composites. 2019;131(September 2018):398-405.

(28) Kchaou, M., Sellami, A., Elleuch, R., Singh, H., "Friction Characteristics of a Brake Friction Material under Different Braking Conditions", Materials and Design. 52 (2013) 533540.

(29) Singh, T., Patnaik, A., "Performance Assessment of LapinusAramid Based Brake Pad Hybrid Phenolic Composites in Friction Braking", Arch Civ Mech Eng Politechnika Wrocławska. 15:1 (2015) 151-161.

(30) Dadkar, N., Tomar, B. S., Satapathy, B. K., Patnaik, A.,
"Performance Assessment of Hybrid Composite Friction Materials Based on Flyash - Rock Fibre Combination", Materials and Design. 31:2 (2010) 723-731.

(31) Singh, T., Patnaik, A., Chauhan, R., Rishiraj, A., " Assessment of Braking Performance of LapinusWollastonite Fibre Reinforced Friction Composite Materials", J. King Saud Univ.Eng Sci. 29 (2015) 183-190.

(32) Kuma, M., Satapathy, B. K., Patnaik, A., Kolluri, D. K., Tomar, B. S., "Evaluation of Fade-Recovery Performance of Hybrid Friction Composites Based on Ternary Combination of Ceramic-Fibers, Ceramic-Whiskers, and Aramid-Fibers", J Appl Polym Sci. 124 (2012) 3650-3661.

(33) Rajan, B. S., Balaji, M. A. S., Sathickbasha, K., Hariharasakthisudan, P., "Influence of Binder on Thermomechanical and Tribological Performance in Brake Pad", Tribol Ind. 40:4 (2018) 654-669.

(34) Bijwe, J., Kumar, M., Gurunath, P. V., Desplanques, Y., Degallaix, G., "Optimization of Brass Contents for Best Combination of tribo-performance and thermal conductivity of non-asbestos organic (NAO) friction composites. Wear [Internet]. 2008 Aug;265(5-6):699-712. Available from: http://linkinghub.elsevier.com/retrieve/pii/S0043164807007 $79 \mathrm{X}$

(35) Lee, J., Lee, J., Kwon, S., Kim, J., "Effect of Different Reinforcement Materials on The Formation of Secondary Plateaus and Friction Properties in Friction Materials for Automobiles", Tribology International. 120 (2018) 70-79.

(36) Vijay, S. M. R., Singaravelu, D. L., Kchaou, M., " Experimental Investigation on the Tribo-Thermal Properties of Brake Friction Materials Containing Various Forms of Graphite: A Comparative Study", Arab J Sci Eng. 44:2 (2019) 1459-1473.

(37) Yi, G., Yan, F., "Effect of Hexagonal Boron Nitride and Calcined Petroleum Coke on Friction and Wear Behavior of Phenolic Resin-Based Friction Composites", Mater Sci Eng A. $425: 1$ (2006) 330-338.

(38) Saikrishnan, G., "Influence of Iron-Aluminum Alloy on the Tribological Performance of Non-asbestos Brake Friction Materials - a Solution for Copper Replacement", Industrial Lubrication and Tribology, 72:1 (2019) 66-78.

(39) Belhocine, A., Bouchetara, M., "Thermal Behavior of Dry Contacts in the Brake Discs" Int. J. Automotive Eng. 3 (2012) 9-17.

(40) Wang, F., Liu, Y., "Mechanical and Tribological Properties of Ceramic-Matrix Friction Materials with Steel Fiber and Mullite Fiber", J. Mater. 57 (2014) 449-455.

(41) Liu, Y., Ma, Y., Yu, J., Zhuang, J., Wu, S., Tong, J., "Development and Characterization of Alkali Treated Abaca Fiber Reinforced Friction Composites", Compos Interfaces. 6440 (2018) 1-16. 